This document is published in:

International Journal of Industrial Organization (2005), 23 (3-4), 155-181. DOI: http://dx.doi.org/10.1016/j.ijindorg.2005.01.004

(C) 2005 Elsevier B.V. 


\title{
Price wars and collusion in the Spanish electricity market
}

\author{
Natalia Fabra ${ }^{\mathrm{a}, *}$, Juan Toro ${ }^{\mathrm{b}}$ \\ ${ }^{a}$ Universidad Carlos III de Madrid, Spain, and CEPR \\ ${ }^{\mathrm{b}}$ CentrA, Spain
}

\begin{abstract}
We analyze the time-series of prices in the Spanish electricity market by means of a time varyingtransition-probability Markov-switching model. Accounting for changes in demand and cost conditions (which reflect changes in input costs, capacity availability and hydro power), we show that the time-series of prices is characterized by two significantly different price levels. Using a Cournot model among contracted firms, we characterize firms' optimal deviations from a collusive agreement, and identify trigger variables that could be used to discourage deviations. By interpreting the effects of the triggers in affecting the likelihood of starting a price war, we are able to infer some of the properties of the collusive strategy that firms might have followed.
\end{abstract}

JEL classification: C22; L13; L94

Keywords: Electricity markets; Tacit collusion; Markov switching

\section{Introduction}

During the last decade decentralized electricity markets have been created in Britain, Norway, Sweden, the United States, Australia, Argentina, and Spain, to name but a few.

\footnotetext{
* Corresponding author. Economics Department, Universidad Carlos III de Madrid, Calle Madrid 126, 28903 Getafe Madrid, Spain.

E-mail address: natalia.fabra@uc3m.es (N. Fabra).
} 
The details differ from country to country, but the different processes of reform share some common features. These include the breaking up of the formerly vertically integrated companies; the unbundling of generation, transmission, distribution and retailing; the reliance on spot markets as a mean to allocate production and determine prices; and the design of new institutional mechanisms to govern access to the transmission network.

This new form of regulation has raised concerns about the ability of electricity producers to exercise market power and its effects on the efficiency of the market. The recent empirical literature on market power in electricity markets is now vast. The studies have identified strategic bidding and output decisions by individual firms (Borenstein and Bushnell, 1999; Wolak, 2000, 2003; Wolfram, 1998) and have measured the departures of market outcomes from the competitive benchmark (Borenstein et al., 2002; Joskow and Kahn, 2002; Wolfram, 1999). All these studies have focused on the unilateral exercise of market power, but little attention has been devoted to analyze collusive attempts to exercise market power in a dynamic context. ${ }^{1}$ Nonetheless, electricity markets present several features that facilitate the sustainability of collusion more than most other markets: trading takes place on a daily basis and it is organized as a uniform-price auction, ${ }^{2}$ firms are capacity constrained, demand is very inelastic in the short-term, and there is typically a small number of players protected by high entry barriers. Both theory and experience suggest that these factors may allow firms to coordinate their strategies, and hence compete less aggressively with each other over time, through collusive agreements.

The analysis of the performance of the Spanish electricity spot market during 1998 provides a unique opportunity to perform an empirical analysis of firms' dynamic interaction. The availability of detailed data allows the use of changes in prices, firms' market shares and cost fluctuations in order to identify potential attempts to exercise market power in a dynamic context. Moreover, the analysis of this market uncovers interesting effects regarding the link between firms' bidding incentives and contract positions. In the Spanish electricity market, firms are entitled to recover their stranded costs through the so-called Competition Transition Costs (CTCs), which play a similar role as contracts. In particular, given that CTCs are computed as a decreasing function of market prices, they reduce firms' incentives to raise prices. This effect is asymmetric across firms, not only because firms' market shares differ, but also because their (fixed) shares over these payments are asymmetric. It is precisely this asymmetry that makes it feasible to identify the effect of CTCs on firms' bidding incentives.

Fig. 1 plots the time series of demand, prices and the estimated marginal costs and price-cost mark-ups in the Spanish electricity market from January 1998 to December 1998. Prices show a systematic relationship with the evolution of demand and cost conditions throughout most of the time period. However, there are five to seven episodes in which prices fall below their usual prevailing levels. These price jumps seem to be uncorrelated with cost movements, as can be inferred from the series of price-cost markups. Furthermore, this pattern of prices is not consistent with the static models of price

\footnotetext{
${ }^{1}$ Puller's (2000) empirical analysis of collusion in the Californian electricity market is an exception.

${ }^{2}$ In a model applicable to electricity markets, Fabra (2003) shows that the sustainability of collusion is easier in uniform-price auctions as compared to discriminatory auctions.
} 

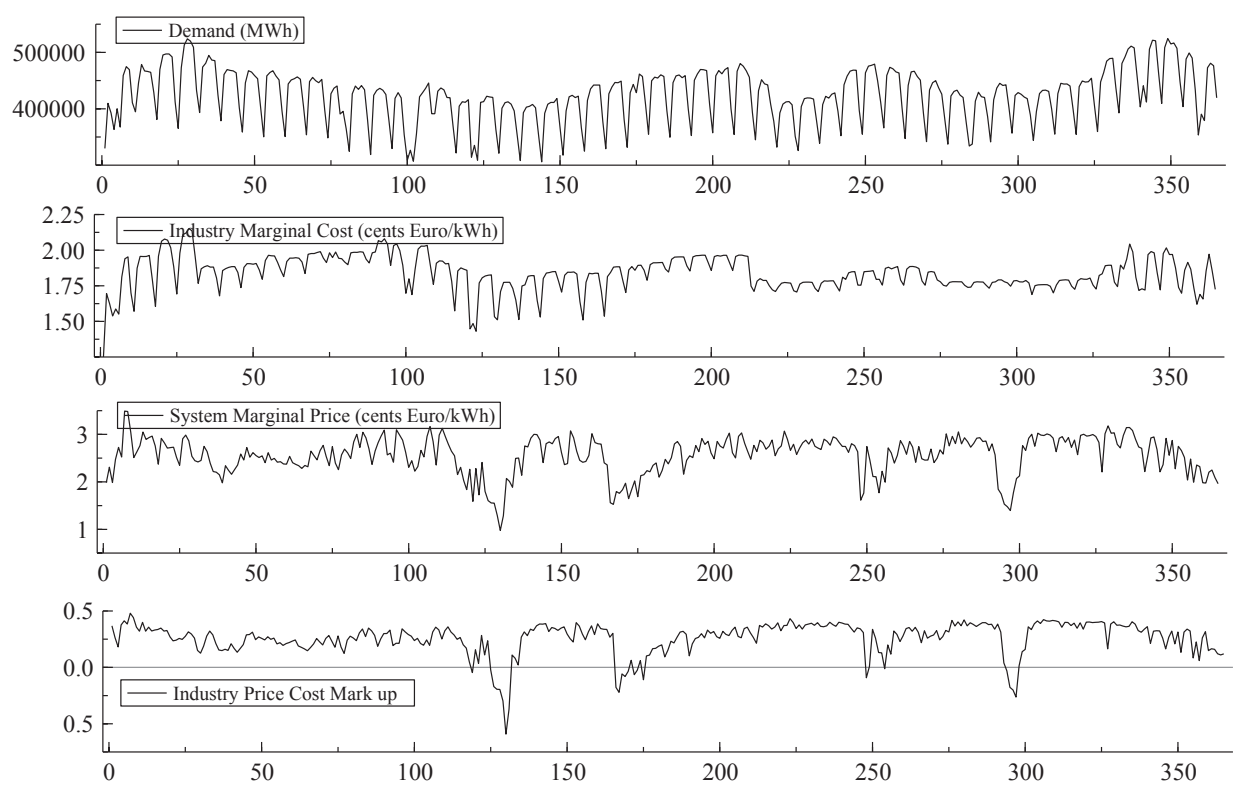

Fig. 1. Total demand, marginal costs, prices and price-cost mark-ups in the Spanish electricity market, 1998.

competition in electricity markets (see Green and Newbery, 1992; von der Fehr and Harbord, 1993), as they predict a positive relationship between demand conditions and prices, after the differences in cost conditions have been taken into account. ${ }^{3}$ The outburst of these periods of intense rivalry thus seems to suggest that firms have followed more complex dynamic strategies than the simple repetition of the static one-shot equilibria.

The main goal of this paper is to empirically evaluate the plausibility of the above conjecture. For this purpose, we first explore the incentive structure faced by the Spanish electricity firms, both under Cournot competition and collusion. We focus on collusive strategies that call firms to produce the monopoly quantity forever unless they observe something that could signal a deviation; in such a case, they are called to revert to the Cournot equilibrium for a finite number of periods before restoring collusion. The aim of the theoretical analysis is two-fold: first, to identify the trigger variables that firms could use to support collusion; and second, to predict how the movements in the trigger variables should affect the probability of starting a price war.

Based on the theoretical predictions, we then model the pattern of pool prices by means of an autoregressive Markov-switching model in the mean with time varying transition probabilities. This process allows for distinct price-cycle phases, with the switching probabilities depending on changes in market prices, firms' market shares and revenues. The statistical model thus enables us to test whether the pattern of prices is characterized

\footnotetext{
${ }^{3}$ Further evidence confirms that firms have not behaved so as to maximize their individual profits. In particular, the mark-ups of the over-contracted firm are positive during most of the sample, contradicting the predictions of the models that assume individual profit maximizing behavior among contracted firms (Newbery, 1998; Wolak, 2000).
} 
by different price levels, whether the effects of the trigger variables are statistically significant, and whether the signs of these effects coincide with those predicted by the theory.

Our results support the hypothesis that two distinct price levels characterize the time series of prices in the Spanish electricity market during 1998. Furthermore, most of the triggers considered appear significant and they report the predicted signs. In particular, the probability of starting a price war increases when the market share and revenues of the over-contracted (under-contracted) firm increase (decrease) and the market price increases above its usually prevailing level. In summary, our results suggest that the Spanish electricity producers might have been alternating between episodes of collusion and price wars, consistently with the theoretical predictions.

The paper is organized as follows. In the next section, we provide an overview of the Spanish electricity industry and its market rules. In Section 3, we analyze a Cournot game among contracted firms to understand firms' incentive structure. Section 4 contains the empirical analysis, including the data description, the empirical model, the summary of the results, and their interpretation. Section 5 of the paper concludes.

\section{The Spanish electricity industry}

In 1997, the Spanish electricity industry experienced fundamental changes. ${ }^{4}$ It evolved from a system in which the allocation of output among the electricity producers was based on yardstick competition to one that relied on market forces as a way of finding the most economic use of the available resources. Under the current regulatory design, transactions are organized through a series of sequential markets - primarily, the day-ahead market and the intra-day markets- and technical processes governed by the System Operator.

The day-ahead market concentrates most of the transactions. ${ }^{5}$ All available production units, excluding those already committed to a physical contract, must participate in it as suppliers. They are asked to submit, each day on a day-ahead basis, the minimum prices at which they are willing to make their generation available in each of the 24 hourly markets. ${ }^{6}$ The demand side is comprised of the distributors, retailers, external agents and qualified consumers, who are also required to submit the maximum prices at which they are willing to consume electricity, and commit in a similar fashion as suppliers. On the basis of these supply and purchase bids, the Market Operator constructs the industry supply and demand curves, ranking the production and demand units in increasing and decreasing merit order, respectively. The intersection between the industry supply and demand curves determines the market clearing price (the so-called System Marginal Price

\footnotetext{
4 The reforms were implemented through the Electricity Law 54/1997 of 27 November 1997. See Crampes and Fabra (in press), Arocena et al. (1999) and Fabra Utray (2004) for an overview and discussion.

${ }^{5}$ In 1998 , the daily market concentrated $99 \%$ of all the electricity traded.

${ }^{6}$ Sale and purchase bids can be made by considering from 1 to 25 energy blocks in each hour, with the proposed price. The bid schedules have to be increasing (decreasing) in the quantity offered (demanded). The supply bids can be simple, or they can include additional conditions, such as indivisibility, load gradient, minimum income and scheduled shutdown.
} 
Table 1

Installed capacity by firm and technology (MW), 1998 (source: CNE, 2000)

\begin{tabular}{lcccccc}
\hline Firm/technology & Hydro & Coal & Fuel/gas & Nuclear & Total MW & Shares \\
\hline Endesa & 6134 & 6684 & 3869 & 3185 & 19,872 & 45.6 \\
Iberdrola & 8175 & 1141 & 3258 & 3533 & 16,407 & 37.7 \\
Unión Fenosa & 1733 & 1972 & 784 & 765 & 5254 & 12.1 \\
Hidrocantábrico & 410 & 1127 & 0 & 149 & 1686 & 3.9 \\
Total MW & 16,452 & 11,224 & 8231 & 7632 & 43,539 & 100.0 \\
Capacity shares & 37.8 & 25.8 & 18.9 & 17.5 & 100.0 & \\
\hline
\end{tabular}

or SMP), which will be received (paid) by all suppliers (demanders) which offered to produce (consume) at lower or equal (greater or equal) prices. The System Operator has the responsibility of studying and solving the technical constraints that may have derived from the day-ahead market. Closer to real time, the intra-day market sessions allow market participants to fine-tune their positions previously undertaken in the day-ahead market. The physical balance in the network between the production and the consumption of electricity is ensured at all times by the System Operator through the ancillary services markets and other technical processes.

The basic structure of the Spanish electricity industry was transformed during the 1990s as a result of a consolidation process among the numerous regional electricity companies. ${ }^{7}$ The result was a highly concentrated industry, both horizontally and vertically. ${ }^{8}$

The two largest participants-Endesa and Iberdrola-control almost $80 \%$ of total available generating capacity, and the remaining $20 \%$ is divided among two smaller firms-Unión Fenosa and Hidrocantábrico-and several fringe companies. Technology mixes vary widely across firms: whereas Endesa owns more than half of total thermal capacity, Iberdrola controls around a half of total hydro power. Table 1 summarizes the capacity shares by company and technology type in the Spanish electricity market.

Generators have three main sources of revenues: market revenues, capacity payments, and stranded cost recovery payments. Firstly, as already described, a generator may earn revenues through the day-ahead, the intra-day and ancillary services markets. In these markets, each generator's revenue is given by the market clearing price in the relevant demand period, times its quantity dispatched. Secondly, all the production units that participate in the day-ahead market receive a capacity payment per unit of capacity declared available. Given that firms earn capacity payments independently of their pricing decisions, these payments should have had no impact on the pattern of prices. We will therefore omit them from our analysis. ${ }^{9}$

\footnotetext{
${ }^{7}$ Part of this consolidation process was government-led. One remarkable instance of this was the government's decision to strengthen Endesa prior to its privatization in 1996, by allowing it to acquire FECSA and Sevillana, which controlled 10\% and 9\% of total capacity, respectively (see Marı'n and Garc1'a-D1'az, 2003).

${ }^{8}$ Distribution remains a regulated activity. In 1998, large customers (with annual consumption exceeding 15 $\mathrm{GWh}$ ) were qualified to contract with a competitive retailer or to participate directly in the market. The volume of electricity acquired by qualified consumers represented a very small fraction of the total market volume (1000 GWh versus 154,000 GWh over 1998).

${ }^{9}$ As a robustness check, the empirical analysis was also carried out including the capacity payment (i.e. using the final price rather than the spot market price). The results were essentially unchanged.
} 
Last, the incumbent generators are entitled to recover their stranded costs through the socalled Competition Transition Costs (CTC) during a 10-year period. The maximum amount of these payments was computed as the difference between the net present value of the revenues that firms were entitled to receive under the former regulatory regime and firms' market expected revenues, under the assumption that the competitive market price would be $3.6 \mathrm{c} / \mathrm{kWh}$ on average. The amount of CTCs to be paid to the whole industry in a particular year is computed as the difference between the total revenues earned through the regulated tariff and the regulated costs. ${ }^{10}$ The Law 54/1997 established that this residual amount would be shared among firms on the basis of some predetermined shares: $51.2 \%$ for Endesa, 27.1\% for Iberdrola, 12.9\% for Unión Fenosa and 5.7\% for Hidrocantábrico.

Two conditions were imposed on the value of the CTCs to be received by a firm over the transition period. First, if the average price received by a firm exceeded $3.6 \mathrm{c} / \mathrm{kWh}$, the extra revenues should be deducted from the firm's maximum CTC entitlement. And second, a firm's CTC revenues could not exceed the maximum entitlement established by the Law 54/1997. These two conditions imposed a price-cap and a price-floor on the pool price. On the one hand, it would not be profitable for any firm to raise prices over $3.6 \mathrm{c} /$ $\mathrm{kWh}$, as any increase in market revenues would be offset by the reduction in the firm's total CTC entitlement. ${ }^{11}$ On the other hand, it would not be profitable to reduce prices to a level below one that allowed a firm to obtain its maximum entitlement, given that the reduced market revenues would not be compensated by an increase in its CTC revenues. ${ }^{12}$

In the next section we present and solve a simple game that incorporates some of the features of the Spanish electricity market that are relevant in understanding firms' pricing incentives.

\section{The theoretical framework}

Consider an industry in which two firms simultaneously decide how much to produce, $q_{i}, i=1,2$, at constant marginal $\operatorname{costs} c \geq 0$. The market price is determined as a function of firms' quantity choices, $P\left(q_{1}+q_{2}\right)$, where $P(\cdot)$ is the inverse demand function, which is decreasing in the total quantity produced. Furthermore, we assume that firm $i=1,2$ is entitled to receive an extra-payment $\left[\tau-P\left(q_{i}+q_{j}\right)\right] \alpha_{i}$, where $\tau$ is a fixed tariff and $\alpha_{i}$ is firm $i$ 's (exogenously given) contracted quantity. Firms' contract positions are taken as a proxy for CTCs. We will assume $P\left(\alpha_{1}+\alpha_{2}\right)>c$.

\footnotetext{
${ }^{10}$ Mainly, payments to distributors (who are reimbursed their costs of buying electricity in the spot market plus a rate of return), payments for transmission, payments to generators in the so-called Special Regime (mainly, renewables and cogenerators) and subsidies for burning national coal.

${ }^{11}$ This assertion is valid as long as firms do not discount the future stream of profits very strongly, and as long as they perceive full regulatory certainty about the payment of their total CTC entitlements. This second concern started to play a role from 1999 onwards, when the European Commission opened up an investigation to determine whether the CTCs were State Aids, in which case they would have been banned.

12 The maximum amount of CTCs was fixed at $11,951.5 \mathrm{~m}, 1774.6$ of which were subsidies to national coal, and the rest was the maximum amount to be divided among the incumbent firms. In 1998, firms perceived CTCs which amounted to $633.5 \mathrm{~m}$. The maximum entitlements of Endesa and Iberdrola were reduced by $€ 67.5 \mathrm{~m}$ and $€ 47.15 \mathrm{~m}$, respectively, because their average prices exceeded $3.6 \mathrm{c} € / \mathrm{kW} \mathrm{h}$. See CNE (2000) for a more detailed description.
} 
First, assume that firms choose their quantities non-cooperatively. Firm $i$ 's profit maximization problem given an output level $q_{j}$ of the rival firm, $i=1,2, i \neq j$, is: ${ }^{13}$

$$
\max _{q_{i} \geq 0} \pi_{i}\left(q_{i}, q_{j}\right)=\left[P\left(q_{i}+q_{j}\right)-c\right] q_{i}+\left[\tau-P\left(q_{i}+q_{j}\right)\right] \alpha_{i}
$$

An optimal quantity choice for firm $i$ given its rival's output must therefore satisfy the first-order condition:

$$
P^{\prime}\left(q_{i}+q_{j}\right)\left[q_{i}-\alpha_{i}\right]+P\left(q_{i}+q_{j}\right)-c=0
$$

For each $q_{j}$, we let $R_{i}\left(q_{j}\right)$ denote firm $i$ 's best response function. A pair of quantity choices $\left(q_{1}^{*}, q_{2}^{*}\right)$ is a Nash equilibrium if and only if these quantities satisfy the first-order condition (1) for the two firms.

Second, assume that firms choose quantities so as maximize joint profits. Their maximization problem is given by: ${ }^{14}$

$$
\max _{q \geq 0} \pi^{\mathrm{m}}(q)=[P(q)-c] q+[\tau-P(q)]\left[\alpha_{1}+\alpha_{2}\right]
$$

The monopoly quantity, denoted $q^{\mathrm{m}}$, must satisfy the first-order condition:

$$
P^{\prime}\left(q^{\mathrm{m}}\right)\left[q^{\mathrm{m}}-\left(\alpha_{1}+\alpha_{2}\right)\right]+P\left(q^{\mathrm{m}}\right)-c=0
$$

Therefore, any quantity profile $\left(q_{1}^{\mathrm{m}}, q_{2}^{\mathrm{m}}\right)$ such that $q_{1}^{\mathrm{m}}+q_{2}^{\mathrm{m}}=q^{\mathrm{m}}$ would allow firms to attain monopoly profits. However, as shown in Proposition 1 below, unless each firm's production at the monopoly solution equals its contracted quantity, i.e., $q_{i}^{\mathrm{m}}=\alpha_{i}, i=1,2$, firms will have unilateral incentives to deviate. Proposition 1 further explores the conditions under which a firm will optimally deviate from the monopoly solution by either reducing or increasing output.

Proposition 1. From any quantity profile $\left(q_{1}^{m}, q_{2}^{m}\right)$ such that $q_{1}^{m}+q_{2}^{m}=q^{m}$, firm is optimal deviation is to reduce output if and only if the rival is over-contracted at the monopoly solution. Formally, $R_{i}\left(q_{j}^{m}\right)<q_{i}^{m} \Leftrightarrow q_{j}^{m}<\alpha_{j}$.

Proof. We proceed by comparing the marginal profit functions (1) and (2). Graphically, we want to assess whether the slope of the tangent to a firm's individual profit function evaluated at the monopoly quantities is upward or downward sloping.

Extracting (2) from (1) evaluated at $\left(q_{i}^{\mathrm{m}}, q_{j}^{\mathrm{m}}\right)$, for $i=1,2, i \neq j$, we obtain

$$
\frac{\partial \pi_{i}\left(q_{i}^{\mathrm{m}}, q_{j}^{\mathrm{m}}\right)}{\partial q_{i}}-\frac{\partial \pi^{\mathrm{m}}\left(q_{i}^{\mathrm{m}}+q_{j}^{\mathrm{m}}\right)}{\partial q_{i}}=-P^{\prime}\left(q^{\mathrm{m}}\right)-\left[q_{j}^{\mathrm{m}}-\alpha_{j}\right] .
$$

Given that the first-order condition for the monopolist is satisfied with equality, and given that $P^{\prime}(q)<0$, it follows that firm $i$ 's marginal profit function is downward

\footnotetext{
${ }^{13}$ We assume that the objective function is concave in $q_{i}$ so that satisfaction of first order condition is sufficient for $R_{i}\left(q_{j}\right)$ to be firm $i$ 's optimal choice given the production of its rival.

${ }^{14}$ Again, we assume that the objective function is concave in $q$ so that satisfaction of first order condition is sufficient for $q^{\mathrm{m}}$ to be an optimal choice.
} 
sloping at $\left(q_{i}^{\mathrm{m}}, q_{j}^{\mathrm{m}}\right)$ if and only if the rival firm is over-contracted at the monopoly solution, i.e.,

$$
\frac{\partial \pi_{i}\left(q_{i}^{\mathrm{m}}, q_{j}^{\mathrm{m}}\right)}{\partial q_{i}}<0 \Leftrightarrow q_{j}^{\mathrm{m}}<\alpha_{j} .
$$

From the concavity of the profit function, it follows that a firm facing an overcontracted rival deviates from the monopoly solution by reducing output. Note that in a standard game with no contract positions, $q_{j}^{\mathrm{m}}>\alpha_{j}=0$. Hence, in the absence of contracts, we obtain the standard result that a firm's best response is always to increase output.

To illustrate our previous results, suppose that the demand function takes the linear form $P(q)=1-q_{1}-q_{2}$. Assumption $P\left(\alpha_{1}+\alpha_{2}\right)>c$ implies $1-\alpha_{1}-\alpha_{2}>0$.

Using (2), the monopoly outcome is characterized by

$$
\begin{aligned}
& q^{\mathrm{m}}=\frac{1+\alpha_{1}+\alpha_{2}}{2} \\
& P\left(q^{\mathrm{m}}\right)=\frac{1-\alpha_{1}-\alpha_{2}}{2} \\
& \pi^{\mathrm{m}}=\left[\frac{1-\alpha_{1}-\alpha_{2}}{2}\right]^{2}+\tau\left[\alpha_{1}+\alpha_{2}\right]
\end{aligned}
$$

Similarly, using the first-order condition (1), we find that firm $i$ 's reaction function is ${ }^{15}$

$$
R_{i}\left(q_{j}\right): q_{i}=\frac{1-q_{j}}{2}+\frac{\alpha_{i}}{2}, i=1,2, i \neq j
$$

Solving the system of reaction functions, the Cournot equilibrium outcome is characterized, for $i=1,2$, by

$$
\begin{aligned}
& q_{i}^{*}=\frac{1-\alpha_{j}+2 \alpha_{i}}{3} \\
& P\left(q_{i}^{*}, q_{j}^{*}\right)=\frac{1-\alpha_{1}-\alpha_{2}}{3} \\
& \pi_{i}\left(q_{i}^{*}, q_{j}^{*}\right)=\left[\frac{1-\alpha_{i}-\alpha_{j}}{3}\right]^{2}+\tau \alpha_{i} .
\end{aligned}
$$

By comparing the monopoly and the Cournot solutions, note that the monopoly price exceeds the Cournot price. Nevertheless, whenever firms' contracted quantities are sufficiently large, i.e., $\alpha_{1}+\alpha_{2}>1 / 3$, collusion among contracted firms yields lower prices

\footnotetext{
15 Note that a firm's contracted quantity shifts its reaction function out, but does not affect its slope.
} 
than Cournot competition among non-contracted firms. That is, contracts make colluding firms more aggressive, even absent price wars.

To analyze whether a deviant firm increases or decreases its production with respect to the monopoly solution, we extract $q_{i}^{\mathrm{m}}$ from the reaction function (3) evaluated at $q_{j}^{\mathrm{m}}$ :

$$
R_{i}\left(q_{j}^{\mathrm{m}}\right)-q_{i}^{\mathrm{m}}=\frac{q_{j}^{\mathrm{m}}-\alpha_{j}}{2}
$$

Hence, as stated in Proposition 1 above, the optimal deviation involves reducing output if the rival firm is over-contracted.

Last, we are interested in identifying the observable consequences of firms' optimal deviations. Building on Proposition 1, if a firm facing an over-contracted rival deviates, it would do so by reducing its output. Such a deviation would cause a reduction in its market share, an increase in prices, and accordingly, an increase in its rival's market revenues. Similarly, if a firm facing an under-contracted rival deviates, it would do so by increasing output. Such a deviation would cause an increase in its market share, a reduction in prices, and accordingly, a reduction in its rival's market revenues.

The following corollary summarizes these effects.

Corollary 1. Index firms such that firm 1 is over-contracted and firm 2 is undercontracted, i.e., $q_{1}^{m}<\alpha_{1}$ and $q_{2}^{m}>\alpha_{2}$ :

(i) An optimal deviation by either firm would cause a reduction (increase) in firm 2 's (firm 1's) market share. If $q_{1}^{m}>q_{2}^{m}$; it would also lead to an increase in the Herfindahl-Hirschman Index (i.e., the sum of the squared market shares).

(ii) An optimal deviation by firm 1 would reduce prices and firm 2 's market revenues. An optimal deviation by firm 2 would increase prices and firm 1 's market revenues.

\subsection{Empirical predictions}

The Cournot model developed above allows us to derive some empirical predictions. From Fig. 2, note that Endesa is over-contracted, that Iberdrola is under-contracted, and that Endesa's production exceeds Iberdrola's during most of the sample. Hence, applying Corollary 1, the empirical findings listed below would be consistent with firms following some sort of collusive strategy that calls firms to compete fiercely with each other only after observing something that could signal a deviation (in the right direction).

Changes in firms' market shares: The probability of starting a price war increases following a reduction in Iberdrola's market share and an increase in Endesa's market share. Equivalently, price wars are more likely following an increase in the HHI.

Changes in prices and firms' market revenues: If a price increase makes a price war more likely, an increase in Endesa's market revenues should also increase the probability of starting a price war. Alternatively, if a price reduction makes a price war more likely, a reduction in Iberdrola's market revenues should also increase the probability of starting a price war. 

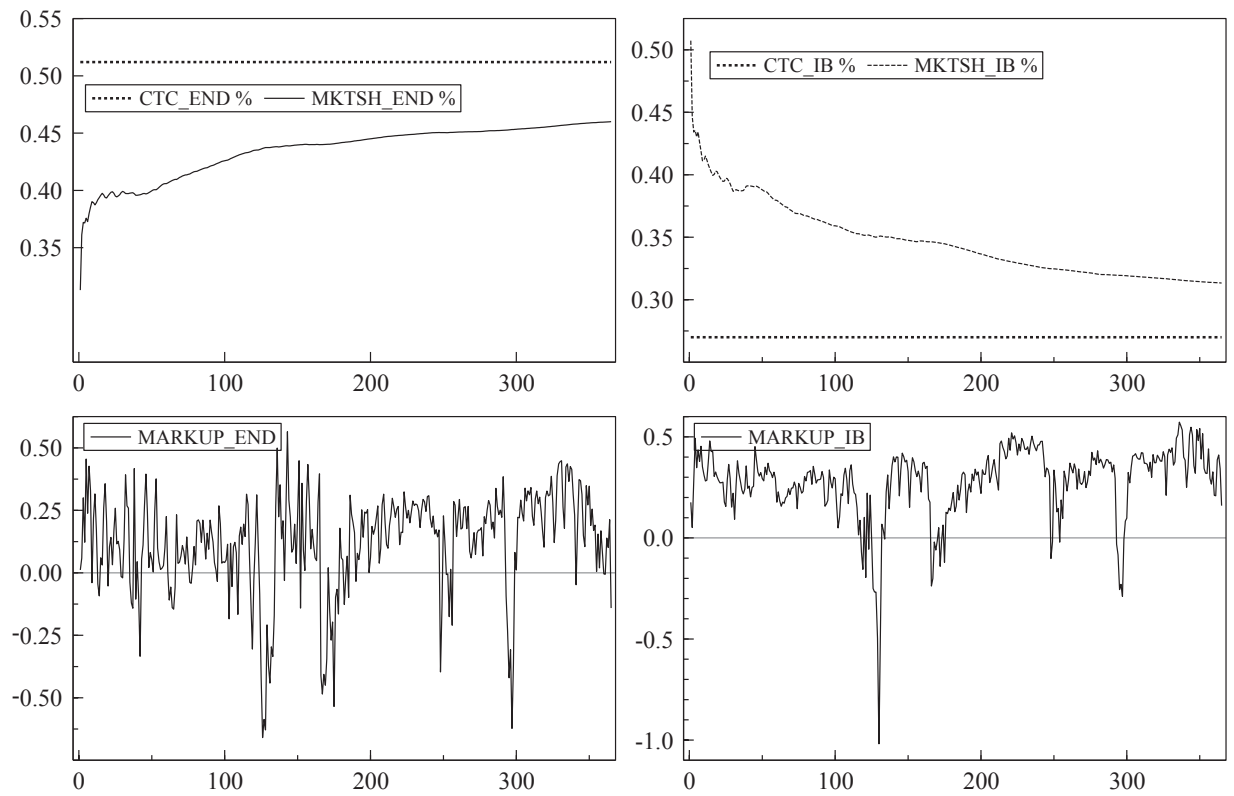

Fig. 2. Endesa's and Iberdrola's market shares, CTC shares and mark-ups, 1998.

Note that the first (second) of the two predictions concerning the movements in prices and firms' market revenues would be consistent with a collusive strategy designed to discourage Iberdrola (Endesa) from deviating, given that an optimal deviation by Iberdrola (Endesa) would lead to a price increase (decrease). On the contrary, we could unambiguously conclude that firms are not following the type of collusive strategies analyzed above if the empirical findings contradict at least one of the above predictions - for instance, if price wars are more likely following price decreases (increases) and increases (decreases) in Iberdrola's (Endesa's) market share.

\section{The empirical analysis}

\subsection{Data description}

For the empirical analysis, we will be using detailed daily data on price, quantities and other variables, some of which are expressed at the industry level, at the firm level, or at the plant level. The sample covers the period from January 1998 through December 1998. Among our variables, we will use the daily aggregate industry production and the daily quantities produced by Endesa and Iberdrola, which we will denote by $Q_{t}, Q_{t}^{\mathrm{END}}$ and $Q_{t}^{\mathrm{IB}}$, respectively. All the quantity variables are measured in MWh. Our price variable is denoted $\mathrm{SMP}_{t}$, which represents the demand-weighted average price in the daily market; it is measured in $\mathrm{c} € / \mathrm{kWh}$. 
In addition, we have constructed estimates of marginal costs and mark-ups (Borenstein et al., 2002; Joskow and Kahn, 2002; Wolfram, 1999 use similar estimation techniques). For this purpose, we have first derived the shot-run thermal cost curve at the firm level by estimating the marginal production costs for each generating plant, on a daily basis. ${ }^{16}$ The short-run marginal costs of a thermal plant (including nuclear, coal, oil and natural gas plants) depend on the type of fuel it burns, the cost of the fuel, the plant's heat rate (i.e., the efficiency rate at which each plant converts the heat content of the fuel into output), and the short-run variable cost of operating and maintaining the plant (O\&M). ${ }^{17} \mathrm{We}$ have assumed that the costs of the fossil-fuels are those negotiated daily in the international input markets. ${ }^{18}$ In addition, to calculate the cost of the coal plants, we have added an estimate of transportation costs based on the distance between each plant and the nearest harbor where coal is delivered. Last, we have assumed that the available capacity of each plant equals its average availability over a given month in those days in which the plant was not subject to scheduled maintenance or forced outages; a plant's available capacity is assumed to be zero otherwise. ${ }^{19}$ By aggregating the capacities of a firm's thermal plants in increasing cost order, we obtain an estimate of its thermal cost curve in a given day (see Fig. 3).

To obtain hourly marginal cost estimates, we need to intersect each firm's thermal cost curve with its thermal production in every hour, i.e., its total production net of its hydro production. For this purpose, we need to assume how firms allocate total hydro production during the day, given that we lack information on the hourly figures. Our data set distinguishes between each firm's daily pondage hydro and run of the river. Whereas firms can choose when to allocate the former, they cannot choose when to produce with the latter. Hence, we have allocated run of the river production evenly over the day. For pondage hydro, we have assumed that firms use it non-strategically and allocate it to high demand hours. This results in firms equalizing thermal production across the hours in which they allocate pondage hydro power, i.e., firms peak-shave each hour. Bushnell (2003) finds that strategic firms may have an incentive to increase

\footnotetext{
16 There are intertemporal and operational constraints that affect firms' costs (e.g. start-up costs or ramping rates). Our cost estimation does not take these into account (see Borenstein et al., 2002 for a discussion of how this could affect the estimates).

${ }^{17}$ The information on the types of fuel burned by each plant, together with their heat rates and operating and maintenance costs, has been obtained from Red Eléctrica de España (REE is the Spanish Transmission Owner and System Operator).

${ }^{18}$ We have not considered firms' obligation to burn domestic coal, and the subsidies obtained from so doing. For coal units, we use the MCIS Index, for fuel units we use the F.O. 1\% CIF NWE prices, and for gas units we use the Gazexport-Ruhrgas prices. All series are in $\mathrm{c} € /$ te. We have obtained this information from UNESA (the Spanish National Union of Electricity companies). For nuclear plants, we have assumed a fixed input cost equal to $0.5 \mathrm{c} \in /$ te; this does not affect the results as nuclear plants are never marginal.

${ }^{19}$ In a study of the British electricity market, Wolfram (1999) assigns each plant a capacity below its declared capacity to capture the strategic withholding aimed at increasing capacity payments (Patrick and Wolak, 1997). In the Spanish electricity market, capacity payments are fixed per MW declared available, implying that firms do not have incentives to under-declare their available capacities. Nevertheless, it must be noted that the scheduling of planned outages for maintenance may be subject to strategic considerations (e.g. it may be profitable to shift scheduled outages from off-peak to on-peak periods, see Patrick and Wolak, 1997 for evidence on this).
} 


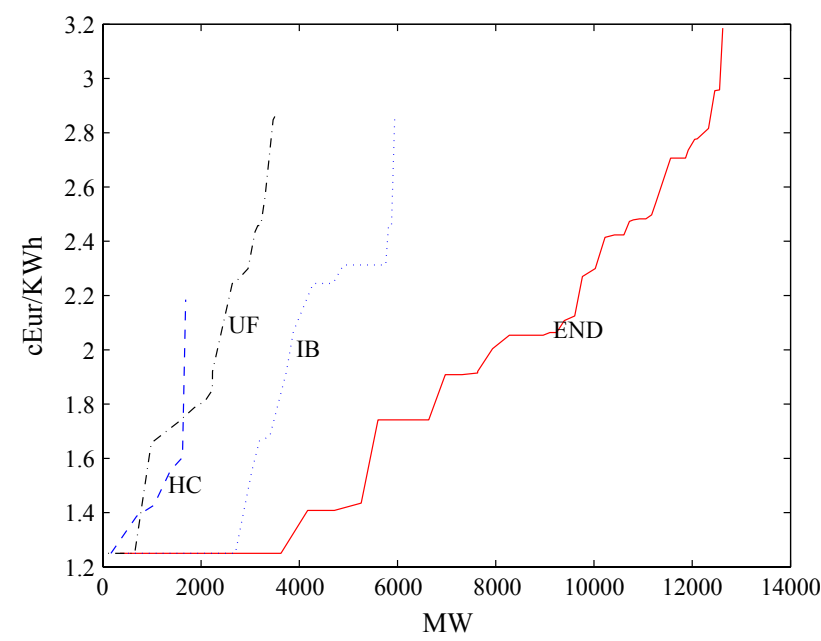

Fig. 3. Representative thermal cost curves at the firm level (on 27/12/98).

hydro production in off-peak hours, rather than on-peak hours, thereby distorting the efficient use of hydro resources. Our methodology does not fully exclude this kind of strategic behavior given that we only assume non-strategic hydro allocation over the course of a day, i.e., firms could still be strategically allocating hydro over the year. Accordingly, we do not expect that the assumed peak-shaving procedure would considerably bias our cost estimates (or at least to the extent that the qualitative nature of the results would be reversed).

Since we will be using daily figures, we have computed demand-weighted marginal cost estimates. In the empirical analysis, we will be using marginal cost estimates for Endesa and Iberdrola only, these are denoted $\mathrm{MC}_{t}^{\mathrm{END}}$ and $\mathrm{MC}_{t}^{\mathrm{IB}}$. We have also computed firms' price-cost mark-ups, which are denoted Markup ${ }_{t}^{\text {END }}$ and Markup ${ }_{t}{ }^{\mathrm{IB}}$ for Endesa and Iberdrola (see Fig. 2).

We have constructed additional variables aimed at capturing firms' strategic behavior. The choice of these variables is based on the theoretical discussion presented in Section 3 . The variables $\Delta$ Share $_{t-1}^{\mathrm{END}}$ and $\Delta$ Share $_{t-1}^{\mathrm{IB}}$ are intended to capture a plausible trigger in an industry geared by a collusive agreement that switches to a price war when a firm's market share suffers a suspiciously large change (either positive or negative). They are measured as percentage changes in the firm's market share with respect to the previous period's value (lagged one period). The trigger variable $\Delta \mathrm{HHI}_{t-1}$, which represents the one period lagged value of changes in the Herfindahl-Hirschman index (i.e., the sum of the squared market shares of all firms in the industry), captures the changes in all firms' market shares. The variables $\Delta \operatorname{Rev}_{t-1}^{\mathrm{END}}$ and $\Delta \operatorname{Rev}_{t-1}^{\mathrm{IB}}$ are intended to capture a similar trigger, based on changes in firms' market revenues. Last, we consider the lagged changes in the weekly average price, $\Delta \overline{\mathrm{SMP}}_{t-1}$.

The changes in firms' market shares and revenues shares depict a strong weekly seasonal component that would enter into the definitions of the trigger variables. In order 
Table 2

Summary statistics

\begin{tabular}{|c|c|c|c|c|}
\hline & Mean & Variance & Min & Max \\
\hline$Q_{t}$ & 423.35 & 47.462 & 305.95 & 524.50 \\
\hline$Q_{t}^{\mathrm{END}}$ & 195.91 & 26.412 & 119.17 & 257.60 \\
\hline$Q_{t}^{\mathrm{IB}}$ & 131.06 & 19.769 & 89.480 & 190.88 \\
\hline $\mathrm{SMP}_{t}$ & 2.5525 & 0.3891 & 0.97613 & 3.1791 \\
\hline $\mathrm{MC}_{t}^{\mathrm{END}}$ & 2.5124 & 0.3914 & 1.2500 & 3.2830 \\
\hline $\mathrm{MC}_{t}^{\mathrm{IB}}$ & 2.4592 & 0.3577 & 1.3270 & 3.1098 \\
\hline Markup $_{t}^{\mathrm{END}}$ & -0.01310 & 0.2415 & -1.0229 & 0.5645 \\
\hline Markup $_{t}^{\text {IB }}$ & 0.00176 & 0.2671 & -1.8256 & 0.5494 \\
\hline$\Delta$ Share $_{t-1}^{\text {END }}$ & 0.0005 & 0.0210 & -0.09159 & 0.0992 \\
\hline$\Delta$ Share $_{t-1}^{\mathrm{IB}}$ & -0.0008 & 0.0300 & -0.11032 & 0.1344 \\
\hline$\Delta \mathrm{HHI}_{t-1}$ & 0.0002 & 0.0124 & -0.03820 & 0.0410 \\
\hline$\Delta \overline{\mathrm{SMP}}_{t-1}$ & -0.0021 & 0.1712 & -0.53367 & 1.0237 \\
\hline$\Delta \operatorname{Rev}_{t-1}^{\mathrm{END}}$ & 0.0016 & 0.1643 & -1.0392 & 0.9913 \\
\hline$\Delta \operatorname{Rev}_{t-1}^{\mathrm{IB}}$ & 0.0027 & 0.1426 & -0.73729 & 0.7650 \\
\hline$\Delta$ Share $_{\mathrm{w}}^{\mathrm{END}}$ & 0.0023 & 0.0221 & -0.0601 & 0.0556 \\
\hline$\Delta$ Share $_{\mathrm{w}}^{\mathrm{IB}}$ & -0.0023 & 0.0374 & -0.1059 & 0.1031 \\
\hline$\Delta \mathrm{HHI}_{\mathrm{w}}$ & 0.0014 & 0.0096 & -0.0236 & 0.0284 \\
\hline$\Delta \overline{\mathrm{SMP}}_{\mathrm{w}}$ & -0.0508 & 0.2860 & -0.5336 & 1.0237 \\
\hline$\Delta \operatorname{Rev}_{\mathrm{w}}^{\text {END }}$ & -0.0408 & 0.2956 & -1.0392 & 0.9913 \\
\hline$\Delta \operatorname{Rev}_{\mathrm{w}}^{\mathrm{IB}}$ & -0.0490 & 0.2327 & -0.7372 & 0.7650 \\
\hline $\operatorname{Dist}_{t}^{\mathrm{IB}}$ & 170.84 & 22.297 & 115.04 & 230.33 \\
\hline Avail $_{t}$ & 16.812 & 0.5276 & 15.805 & 17.772 \\
\hline
\end{tabular}

Variable definitions: $Q_{t}$ : aggregate industry production, $Q_{t}^{\mathrm{END}}$ and $Q_{t}^{\mathrm{IB}}$ : Endesa's and Iberdrola's production, $\mathrm{SMP}_{t}$ : System Marginal Price; $\mathrm{MC}_{t}^{\mathrm{END}}$ and $\mathrm{MC}_{t}^{\mathrm{IB}}$ : firms' marginal costs; Markup ${ }_{t}^{\mathrm{END}}$ and Markup ${ }_{t}^{\mathrm{IB}}$ : firms' pricecost mark-ups; $\Delta$ Share $_{t-1}^{\mathrm{END}}, \Delta \mathrm{Share}_{t-1}^{\mathrm{END}}$, and $\Delta \mathrm{HHI}_{t-1}$ : changes in firms' market shares and changes in the $\mathrm{HHI}$ concentration index, $\Delta \overline{\mathrm{SMP}}_{t-1}$ : changes in the weekly average price; $\Delta \operatorname{Rev}_{t-1}^{\mathrm{END}}$ and $\Delta \mathrm{Rev}_{t-1}^{\mathrm{IB}}$ : firms' revenue changes; the subscript $\mathrm{w}$ denotes that statistics are computed on a five period window prior to observing negative mark-ups for Endesa; Dist ${ }_{t}^{\mathrm{IB}}$ : Iberdrola's distribution, and Avail $t_{t}$ : available thermal capacity.

to only consider their unexpected changes, the associated trigger variables have been constructed on deseasonalized values of production levels and revenues. ${ }^{20}$

\subsection{Summary statistics}

Table 2 provides summary statistics of the variables used in our analysis. The first four rows of Table 2 contain the summary statistics for the aggregate industry production, the production of the individual companies, and prices. Notably, prices are highly volatile, and their drops are more pronounced than their increases. The minimum price recorded $(0.9761 \mathrm{c} € / \mathrm{kWh})$ implies a drop of over $50 \%$ in relation with its mean value, whereas the maximum price recorded (3.1791 $\mathrm{c} € / \mathrm{kWh})$ implies an increase of no more than $25 \%$.

\footnotetext{
20 The deseasonalization is implemented using an unobserved component model. This model is estimated in the series of production and revenues of each of the generators and the Kalman filter is used to extract the different components. A local trend model with trigonometric seasonal and an irregular component is chosen as the benchmark specification. The estimated models are available from the authors upon request.
} 
The next four rows in Table 2 include summary statistics for marginal costs and the pricecost markups of Endesa and Iberdrola. Whereas the volatility of firms' marginal costs does not differ much from that of prices, the minimum marginal costs registered imply that the percentage reductions in marginal costs in relation with the mean are much smaller than those for prices. This seems to suggest that the price declines are not induced by proportional reductions in marginal costs. Indeed, the price-cost markups for both firms record negative values, attaining drops of $180 \%$ in the case of Iberdrola and maximum increases around 50\% for both companies (the timing of these extreme values can be seen in Fig. 2).

The next six rows record statistics for the trigger variables. Though the changes of most of these variables seem to average zero, they are characterized by a high variance. Percentage changes in the market share of Endesa and Iberdrola can attain values of around $10 \%$ from one day to the other, both in the downside and in the upside. Percentage changes in the market revenues of both companies can have swings of over $90 \%$ for Endesa, and well above $70 \%$ for Iberdrola.

As a prior check out of whether the trigger variables can precede, and in some way explain, the price declines, we have calculated summary statistics for these variables for the 5 days prior to the occurrence of negative price-cost markups for Endesa. These summary statistics are presented in rows 15 to 20 in Table 2, and are denoted with the subscript w. ${ }^{21}$ The results suggest that price declines are related to the variables we have chosen as triggers: changes in firms' market shares, changes in prices, and changes in firms' market revenues. In those periods preceding Endesa's negative markups, there is an increase in the average percentage change of Endesa's market share as compared with the values obtained when using the whole sample period (0.0023 versus 0.0005$)$. Also, there is a sharper drop in the change of Iberdrola's market share $(-0.0023$ versus -0.0008$)$. Moreover, the average drop in prices is more pronounced in periods preceding negative markups of Endesa as compared with the average change in prices computed for the whole sample period $(-0.0508$ versus -0.0021$)$. Last, these facts translate into sharper changes in firms' revenues $(-0.0408$ versus -0.0016 for Endesa, and -0.0490 versus -0.0027 for Iberdrola).

The last two rows of Table 2 include statistics for the demand distributed by Iberdrola and the available thermal capacity in the industry. These two variables will be used as instrumental variables in the empirical model, which we describe next.

\subsection{The empirical model}

As our statistical model we will consider an autoregressive Markov-switching model in the mean with time varying transition probabilities (TVTP). The TVTP model encompasses the fix transition probability model (FTP), as it may allow the switching probabilities to either change or not change over time. Furthermore, in contrast to the FTP in which the expected duration of a phase of low/high prices is constant, the TVTP is linked to the notion of time-varying duration in the Markov-switching framework.

\footnotetext{
${ }^{21}$ We thank the Editor for suggesting this idea. Similar statistics were calculated for the 5 days prior to negative markups by Iberdrola. The results, which are close to those reported here, are available from the authors upon request.
} 
The autoregressive TVTP Markov-switching model of prices allows for distinct pricecycle phases (collusive price phase/price war phase) with state-dependent means, and for dynamics of prices with the lagged predetermined variables. ${ }^{22}$ The state of prices is not known with certainty. The econometrician can neither observe the state of prices nor deduce the state directly. These states are assumed to be path dependent and evolve according to a first-order Markov process with TVTP coefficients. The TVTP model with state-dependent mean can be presented as: ${ }^{23}$

$$
\begin{aligned}
& \mathrm{SMP}_{t}=\mu_{S_{t}}+\beta \mathbf{Z}_{t}+v_{t}^{s} \\
& \mu_{S_{t}}=\mu_{0}\left(1-S_{t}\right)+\mu_{1} S_{t} \\
& S_{t}=0,1 .
\end{aligned}
$$

where $\mathrm{SMP}_{t}$ is the system marginal price in period $t ; \mu_{S_{t}}$ is the mean of prices in state $S_{t}$; which can either be a collusive state, $S_{t}=0$, or a price war state, $S_{t}=1$ (i.e., $\mu_{0} \geq \mu_{1}$ ), and $\mathbf{Z}_{t}$ is a group of variables that are likely to influence prices and measured as deviations from their means.

The stochastic process for $S_{t}$ can be summarized by the following transition probability:

$$
P\left(S_{t}=s_{t} \mid S_{t-1}=s_{t-1}, w_{t-1}\right),
$$

where $s_{t}$ is a possible realization of the random variable $S_{t}$. We assume serial correlation of the states (e.g. a collusive period is likely to be followed by another collusive period). The variable $w_{t-1}$ is likely to influence the transition probabilities, and it is henceforth referred to as 'trigger variable'. ${ }^{24,25}$

The matrix of transition probabilities that governs the stochastic process is given by:

$$
\Lambda_{t-1}=\left(\begin{array}{ll}
q\left(w_{t-1}\right) & 1-p\left(w_{t-1}\right) \\
1-q\left(w_{t-1}\right) & p\left(w_{t-1}\right)
\end{array}\right)
$$

\footnotetext{
${ }^{22}$ In this respect, we depart from Ellison (1994) since he allows for autoregressive residuals, which in our view could be a sign of misspecification because of the omission of lagged dependent variables.

${ }^{23} \mathrm{Eq}$. (4) could include the trigger-variables $\left(w_{t-1}\right)$. However, we formulate our model with the trigger-variables influencing only the transition probabilities, to emphasize the contribution of the TVTP on the price dynamics.

${ }^{24}$ Two issues need to be stressed. First, we have explicitly written lagged $w_{t-1}$, because the theory predicts that firms should react immediately after they observe an anomalous behavior of the trigger variables. And second, it might be reasonable to allow the transition probability $p\left(w_{t-1}\right)$ to depend on the number of periods firms have been in a price war, i.e. on duration, $d_{t-1}$. We are aware that omitting the dependence of $p\left(w_{t-1}\right)$ on $d_{t-1}$ might lead to inconsistent estimates of the response of $w_{t-1}$ on $p$. This should not affect our main results however. We are only interested in determining the probability of entering into a price war, $1-q\left(w_{t-1}\right)$; which should not be dependent on duration.

${ }^{25}$ In order to obtain consistent and normally distributed estimates from our maximum likelihood estimators, the trigger-variables chosen should be conditionally uncorrelated with the states, given the current prices (see Engle et al., 1983; Filardo, 1994). This would allow us to estimate consistently our TVTP model using jointly the conditional maximum likelihood estimator (MLE) and the filtering methods proposed in Hamilton (1989). This is the case of our trigger variables.
} 
where $q\left(w_{t-1}\right)=P\left(S_{t}=0 \mid S_{t-1}=0 ; w_{t-1}\right)$ and $p\left(w_{t-1}\right)=P\left(S_{t}=0 \mid S_{t-1}=1 ; w_{t-1}\right)$. In words, $q\left(w_{t-1}\right)$ captures the probability of being in a collusive state $\left(S_{t}=0\right)$ given that the previous period was a collusive state $\left(S_{t-1}=0\right)$ and given the values recorded for the trigger variable in the previous period $\left(w_{t-1}\right)$. That is, the probability of switching to a given state (collusion/price war) depends on the given state and the value of the trigger variable in the previous period.

In searching for a particular functional form of the transition probabilities, we will use the logistic function: ${ }^{26}$

$$
P\left(S_{t}=k \mid S_{t-1}=l, w_{t-1}\right)=\frac{\exp \left(\lambda_{l k, 0}+\lambda_{l k, 1} w_{t-1}\right)}{1+\exp \left(\lambda_{l k, 0}+\lambda_{l k, 1} w_{t-1}\right)}, l, k=0,1 .
$$

where $\left(\lambda_{l k}, l, k=0,1\right)$ are unrestricted parameters. We are interested in characterizing the probability of starting a price war. This is given by

$$
1-q\left(w_{t-1}\right)=P\left(S_{t}=1 \mid S_{t-1}=0, w_{t-1}\right)=1-\frac{\exp \left(\lambda_{00,0}+\lambda_{00,1} w_{t-1}\right)}{1+\exp \left(\lambda_{00,0}+\lambda_{00,1} w_{t-1}\right)} .
$$

Thus the parameter estimate $\lambda_{00,1}$ reflects the influence of $w_{t-1}$ on $1-q\left(w_{t-1}\right){ }^{27}$

With autoregressive dynamics of order 1 the conditional density distribution of $\mathrm{SMP}_{t}$, given $S_{t}, S_{t-1}, \mathrm{SMP}_{t-1}, w_{t-1}$ and $\mathbf{Z}_{t}$, is defined by $f$, and can be written as:

$$
\begin{aligned}
& f\left(\mathrm{SMP}_{t} \mid S_{t}, S_{t-1}, \mathrm{SMP}_{t-1}, w_{t-1}, \mathbf{Z}_{t}\right) \\
& =\sum_{s_{t}=0}^{1} \sum_{s_{t-1}=0}^{1} f\left(\mathrm{SMP}_{t}, S_{t}=s_{t}, S_{t-1}=s_{t-1} \mid \mathrm{SMP}_{t-1}, w_{t-1}, \mathbf{Z}_{t}\right) \\
& \quad=\sum_{s_{t}=0}^{1} \sum_{s_{t-1}=0}^{1} f\left(\mathrm{SMP}_{t} \mid S_{t}=s_{t}, S_{t-1}=s_{t-1}, \mathrm{SMP}_{t-1}, w_{t-1}, \mathbf{Z}_{t}\right) \\
& P\left(S_{t}=s_{t}, S_{t-1}=s_{t-1} \mid \mathrm{SMP}_{t-1}, w_{t-1}, \mathbf{Z}_{t}\right) \\
& \quad=\sum_{s_{t}=0}^{1} \sum_{s_{t-1}=0}^{1} f\left(\mathrm{SMP}_{t} \mid S_{t}=s_{t}, S_{t-1}=s_{t-1}, \mathrm{SMP}_{t-1}, w_{t-1}, \mathbf{Z}_{t}\right) \\
& P\left(S_{t}=s_{t} \mid S_{t-1}=s_{t-1}, w_{t-1}\right) P\left(S_{t-1}=s_{t-1} \mid w_{t-1}\right)
\end{aligned}
$$

\footnotetext{
${ }^{26}$ As in binary response models different specifications are available for mapping the index function $\left(\lambda_{l k, 0}+\lambda_{l k, 1} w_{t-1}, k, l=0,1\right)$ into a probability. We could have tried other alternatives for our transformation function $(F(\cdot))$ such as a normal or a Cauchy cumulative distribution function instead of the logistic specification chosen. However, we have preferred the latter specification since it is more tractable. For the normal and Cauchy cumulative distribution function there is no close form expression for $F(x)$ and it has to be evaluated numerically. This would have increased the amount of calculations in the type of models that we use in the paper which are already very computer intensive.

${ }^{27}$ Note that the sign of marginal effect of $w_{t-1}$ on the probability of starting a price war will have the opposite sign as the $\lambda_{00,1} \mathrm{~s}$.
} 
and the likelihood function is:

$$
L(\theta)=\sum_{t=1}^{T} \ln f\left(\mathrm{SMP}_{t} \mid \operatorname{SMP}_{t-1}, \mathbf{Z}_{t}, w_{t-1} ; \theta\right),
$$

where $\theta$ are the parameters of interest. The states are unobserved by the econometrician and the filter developed in Hamilton (1989) is used to jointly estimate the parameters of the model and the process governing the states.

In order to analyze the pattern of prices in the Spanish electricity market, we will estimate a supply equation of the form,

$$
\mathrm{SMP}_{t}=\beta_{0}+\beta_{1} \mathrm{MC}_{t}^{\mathrm{END}}+\beta_{2} \mathrm{MC}_{t}^{\mathrm{IB}}+\beta_{3} Q_{t}^{\mathrm{END}}+\beta_{4} Q_{t}^{\mathrm{IB}}+\beta_{5} Q_{t}^{\mathrm{R}} .
$$

Our supply equation defines $\mathrm{SMP}_{t}$ as function of a constant, $\beta_{0}$, the marginal cost of the main generators, $\mathrm{MC}_{t}^{\mathrm{END}}$ and $\mathrm{MC}_{t}^{\mathrm{IB}}$; their production levels, $Q_{t}^{\mathrm{END}}$ and $Q_{t}^{\mathrm{IB}}$, and the residual demand not served by them, $Q_{t}^{\mathrm{R}}=\left[Q_{t}-Q_{t}^{\mathrm{END}}-Q_{t}^{\mathrm{IB}}\right]$ (i.e., covered through imports, the production of the non-strategic firms, etc.).

Our previous discussion suggests that in the Spanish electricity market the $\mathrm{SMP}_{t}$ might be better characterized by a changing mean, with two different price levels, and that the dynamics of switching from one price state to the other might be influenced by some strategic variables. In order to formulate Eq. (7) as in (4), we express the variables in deviations from their means and allow the mean of prices to fluctuate between two states. Last, we introduce autoregressive dynamics to allow for cross-price effects. This results in our equation of interest,

$$
\mathrm{SMP}_{t}-\mu_{S_{t}}=\rho\left(\mathrm{SMP}_{t-1}-\mu_{S_{t-1}}\right)+\beta \mathbf{Z}_{t}+v_{t}^{\mathrm{s}}
$$

where $\beta$ is the vector of parameters in the linear part of the model, $\mathbf{Z}_{t}=\left[\mathrm{MC}_{t}^{\mathrm{END}}-\right.$ $\left.E\left(\mathrm{MC}_{t}^{\mathrm{END}}\right), \mathrm{MC}_{t}^{\mathrm{IB}}-E\left(\mathrm{MC}_{t}^{\mathrm{IB}}\right), Q_{t}^{\mathrm{END}}-E\left(Q_{t}^{\mathrm{END}}\right), Q_{t}^{\mathrm{IB}}-E\left(Q_{t}^{\mathrm{IB}}\right), Q_{t}^{\mathrm{R}}-E\left(Q_{t}^{\mathrm{R}}\right)\right]^{\prime}$ is the corresponding vector of variables measured in deviations from their means, the term $v_{t}^{\mathrm{s}} \sim N\left(0, \sigma_{s}\right)$ captures innovations or shocks unmodelled in our supply equation and $\mu_{S_{t}}$ denotes the time varying mean of prices, where $S_{t}$ denotes the state, with $S_{t}=0$ if $t$ is a collusive period (high prices), and $S_{t}=1$ if $t$ belongs to a price war (low prices).

Note that there could be three potential sources of endogeneity of the $\mathbf{Z}_{t}$ variables. The demand not served by the strategic firms, $Q_{t}^{\mathrm{R}}$, and the quantities they produce, $Q_{t}^{\mathrm{END}}$ and $Q_{t}^{\mathrm{IB}}$, are likely to be correlated with innovations in our price Eq. (8). In order to address this endogeneity problem we respectively instrument these variables with weekend dummies, the available thermal capacity in the industry, and the demand distributed by Iberdrola (see Table 2 for summary statistics of these variables). These are all valid instruments as they are correlated with the corresponding variables but unrelated with innovations in prices. The weekend dummies capture most of the variation of the demand not served by the strategic firms and they are unrelated with innovations in prices. Moreover, the thermal available capacity should be correlated with $Q_{t}^{\mathrm{END}}$ and uncorrelated with innovations in prices. Last, the amount distributed by Iberdrola should be related to $Q_{t}^{\mathrm{IB}}$ and unrelated with innovations in prices (the amount served by any distributor is independent of wholesale prices as final consumers pay a regulated tariff, set in advance). 


\subsection{The results and their interpretation}

In our empirical analysis we consider six models that differ in the variables that are used as triggers. The different models are labelled from 1 to 6 , corresponding to the use of $\Delta$ Share $_{t}^{\mathrm{EN}}{ }_{-1}^{\mathrm{D}}, \quad \Delta$ Share $_{t}^{\mathrm{IB}}, \quad \Delta \mathrm{HHI}_{t-1}, \quad \Delta \mathrm{SMP}_{t-1}, \quad \Delta \operatorname{Rev}_{t-}{ }^{\mathrm{END}}{ }_{1} \quad$ and $\Delta \operatorname{Rev}_{t}{ }^{\mathrm{IB}}-1, \mathrm{r}$ e s p e c t $\mathrm{i} \mathrm{v}$ e $1 \mathrm{y}$. Estimates are computed by numerically maximizing the conditional likelihood. ${ }^{28}$ Table 3 reports results for our set of models. The signs of the coefficients associated with the relevant variables are as expected. Increases in the marginal costs of Endesa and Iberdrola induce an increase in prices, as reported by the positive signs of $\beta_{1}$ and $\beta_{2}$. The coefficient of the Endesa's production $\left(\beta_{3}\right)$ is strongly significant and reports a positive coefficient. The point estimate of the coefficient associated with Iberdrola's production $\left(\beta_{4}\right)$ reports a negative sign, though a confidence interval constructed at the $5 \%$ level of significance would also include positive values as well as zero. Finally, the demand not served by the two main generators is strongly significant and the negative sign of $\beta_{5}$ is consistent with the predictions of the model.

Table 3 presents enough evidence to support the hypothesis that two distinct price levels characterize the time series of prices. The point estimates of the state-dependent means are statistically different and their magnitudes differ statistically and economically according to the asymptotic standard errors. The sample dichotomizes in two phases that exhibit a low (price war phase) and a high price (collusive phase), given the technology and production information embodied in Eq. (8).

Table 3 also lists the estimates for the transition probability equation. All of the points estimates of the $\lambda_{00,0}$ and $\lambda_{11,0}$ parameters are statistically significant at the $5 \%$ level; but some of the points estimates of the $\lambda_{00,1}$ and $\lambda_{11,1}$ parameters are not significantly different from zero. Nevertheless, a test for joint significance of these point estimates rejects the null of a FTP model for all models. In more detail, for the parametrization of the transition probability $\left[1-q\left(w_{t-1}\right)\right]$ in Eq. (6), the test for the non-influence of the trigger-variables in the process for the transition probabilities is a test for $H_{0}: \lambda_{00,1}=0$ and $\lambda_{11,1}=0$. The null considers a restricted model where the trigger variables do not influence the transition probabilities of switching, to and from, the two different price states. Under the null of no time variation in the transition probabilities, the FTP model is rejected if $\Psi$ $=2 \times\left(\log (\theta)-\log _{R}(\theta)\right)$ exceeds the $\chi^{2}(2)$, where $\log (\theta)$ and $\log _{R}(\theta)$ are the log-likelihoods of the restricted and unrestricted model. The results for the FTP model indicated a value for the likelihood of $20.9747 .^{29}$ The $p$-values resulting from these tests are reported in the last row of Table 3 . The hypothesis of a FTP is rejected at $5 \%$ for all models. Therefore, our results show that there is further information embodied in the trigger-variables that accounts for the transition dynamics from high to low price states.

In order to quantify the effect of a variation of the trigger variables in the transition probabilities of entering into a price war, we have calculated the marginal

\footnotetext{
${ }^{28}$ In the estimation, we have scaled the quantity variables dividing them by 10,000 in order to put all the variables in a similar scale. This is required for the purpose of facilitating the numerical maximization.

${ }^{29}$ The results of the FTP model are not reported in this paper and are available from the authors upon request.
} 
Table 3

Parameters estimates of the TVTP models

\begin{tabular}{|c|c|c|c|c|c|c|}
\hline & Model $1, \Delta$ Share $_{t-1}^{\mathrm{END}}$ & Model 2, $\Delta$ Share $_{t-1}^{\mathrm{IB}}$ & Model 3, $\Delta \mathrm{HHI}_{t-1}$ & Model 4, $\Delta \overline{\mathrm{SMP}}_{t-1}$ & Model 5, $\Delta \operatorname{Rev}_{t-1}^{\mathrm{END}}$ & Model $6, \Delta \operatorname{Rev}_{t-1}^{\mathrm{IB}}$ \\
\hline log-lik & 27.8975 & 28.5338 & 27.6838 & 27.7454 & 28.4649 & 28.1910 \\
\hline$\rho$ & $0.5209(0.0455)$ & $0.5217(0.0461)$ & $0.5211(0.0452)$ & $0.5173(0.0448)$ & $0.5282(0.0502)$ & $0.5191(0.0441)$ \\
\hline$\beta_{1}$ & $0.1207(0.0318)$ & $0.1209(0.0317)$ & $0.1220(0.0321)$ & $0.1217(0.0317)$ & 0.1207 (0.0319) & $0.1234(0.0319)$ \\
\hline$\beta_{2}$ & $0.0154(0.0154)$ & $0.0152(0.0154)$ & $0.0156(0.0155)$ & $0.0153(0.0154)$ & $0.0153(0.0156)$ & $0.0159(0.0153)$ \\
\hline$\beta_{3}$ & $0.0808(0.0299)$ & $0.0803(0.0301)$ & $0.0818(0.0295)$ & $0.0816(0.0296)$ & $0.0716(0.0322)$ & $0.0828(0.0293)$ \\
\hline$\beta_{4}$ & $-0.0376(0.0348)$ & $-0.0363(0.0347)$ & $-0.0391(0.0349)$ & $-0.0379(0.0345)$ & $-0.0357(0.0348)$ & $-0.0395(0.0346)$ \\
\hline$\beta_{5}$ & $-0.2004(0.0757)$ & $-0.2017(0.0755)$ & $-0.2027(0.0765)$ & $-0.2019(0.0754)$ & $-0.2026(0.0759)$ & $-0.2056(0.0758)$ \\
\hline$\mu_{0}$ & $2.6658(0.0231)$ & $2.6651(0.0231)$ & $2.665(0.0231)$ & $2.6658(0.0229)$ & $2.6643(0.0235)$ & $2.6647(0.0228)$ \\
\hline$\mu_{1}$ & $1.9289(0.0512)$ & 1.9255 (0.0509) & $1.9247(0.0520)$ & $1.9260(0.0505)$ & $1.9369(0.0531)$ & $1.9209(0.0508)$ \\
\hline$\lambda_{00,0}$ & $3.6185(0.3831)$ & $3.6748(0.3948)$ & $3.6080(0.3762)$ & $3.6264(0.3800)$ & $3.6095(0.3866)$ & $3.5963(0.3808)$ \\
\hline$\lambda_{11,0}$ & $1.7934(0.4349)$ & $1.8570(0.4557)$ & $1.7757(0.4401)$ & $1.7504(0.4418)$ & $1.8977(0.5048)$ & $1.9292(0.4819)$ \\
\hline$\lambda_{00,1}$ & $13.0737(14.8481)$ & $12.0412(10.2657)$ & $-42.0927(74.9304)$ & $-0.8752(0.8404)$ & $-1.6093(1.5004)$ & $2.0324(3.8287)$ \\
\hline$\lambda_{11,1}$ & $10.1408(17.4295)$ & $-9.5191(8.9431)$ & $-40.45(92.9327)$ & $-0.1046(1.9421)$ & $2.8551(2.1643)$ & $2.9148(2.6503)$ \\
\hline$\sigma$ & $0.0373(0.0029)$ & $0.0374(0.0029)$ & $0.0374(0.0029)$ & $0.0373(0.0029)$ & $0.0371(0.0030)$ & $0.0373(0.0029)$ \\
\hline
\end{tabular}

Standard errors are in parenthesis. 
Table 4

Marginal effects of the trigger variables on the transition probabilities (based on Model 1 , trigger $\Delta$ Share $_{t-1}{ }^{\mathrm{END}}$ )

\begin{tabular}{lcc}
\hline Trigger variable & $\frac{\partial P\left(S_{t}=1 \mid S_{t-1}=0, \bar{w}_{t-1}\right)}{\partial w_{t-1}}$ & $\frac{1}{T} \sum_{i=1}^{T} \frac{\partial P\left(S_{t}=1 \mid S_{t-1}=0, w_{t-1}\right)}{\partial w_{t-1}}$ \\
\cline { 2 - 3 } & 0.3351 & 0.3474 \\
$\Delta$ Share $_{t-1}^{\mathrm{END}}$ & -0.2937 & -0.3153 \\
$\Delta$ Share $_{t-1}^{\mathrm{B}}$ & 1.0819 & 1.1059 \\
$\Delta \mathrm{HHI}_{t-1}$ & 0.0222 & 0.0226 \\
$\Delta \overline{\mathrm{SMP}}_{t-1}$ & 0.0422 & 0.0445 \\
$\Delta \operatorname{Rev}_{t-1}^{\mathrm{END}}$ & -0.0518 & -0.0538 \\
$\Delta \operatorname{Rev}_{t-1}^{\mathrm{IB}}$ & & \\
\hline
\end{tabular}

effect of increases in $w_{t-1}$ on the transition probability $\left[1-q\left(w_{t-1}\right)\right]$, evaluated at the average $\bar{w}_{t-1}$,

$$
\frac{\partial P\left(S_{t}=1 \mid S_{t-1}=0, \bar{w}_{t-1}\right)}{\partial \bar{w}_{t-1}},
$$

We have also considered the average marginal effect,

$$
\frac{1}{T} \sum_{t=1}^{T} \frac{\partial P\left(S_{t}=1 \mid S_{t-1}=0, w_{t-1}\right)}{\partial w_{t-1}} .
$$

This information is provided in Table 4, and it is complemented in Fig. 4, which depicts the cross plots of the transition probabilities $P\left(S_{t}=1 \mid S_{t-1}=0, w_{t-1}\right)$ with the trigger variables associated with changes in firms' market shares and revenues.

The signs of the marginal effects are consistent with the empirical predictions in Section 3.1. First, the marginal effects of $\Delta$ Share $_{t-1}^{\mathrm{END}}$ and $\Delta \mathrm{Rev}_{t-1}^{\mathrm{END}}$ are positive, whereas those of $\Delta$ Share $_{t-1}^{\mathrm{IB}}$ and $\Delta \operatorname{Rev}_{t-1}^{\mathrm{IB}}$ are negative. That is, increases in Endesa's market share and revenues and reductions in Iberdrola's market share and revenues, increase the probability of entering into a price war phase. The sign of $\Delta \mathrm{HHI}_{t-1}$ is in agreement with those of $\Delta$ Share $_{t-1}^{\mathrm{END}}$ and $\Delta$ Share $_{t-1}^{\mathrm{IB}}$, as an increase in Endesa's market share and a reduction in Iberdrola's market share leads to an increase in industry concentration. Last, the positive sign of $\Delta \overline{\mathrm{SMP}}_{t-1}$ is highly meaningful: in contrast to models of collusion among uncontracted firms, we find that an increase in prices with respect to their usually prevailing level increases (rather than decreases) the probability of starting a price war. Given that a price increase is consistent with Iberdrola's one-shot bidding incentives, this seems to suggest that Iberdrola is considered to be the firm most likely to defect from the collusive agreement. ${ }^{30}$

\footnotetext{
30 The recent performance of the Spanish electricity market shows that Iberdrola has decided, in the light of our analysis, to 'defect' forever. In November 2003, Iberdrola proposed to eliminate the CTC payments, even if there was still a residual amount of CTCs to be received. In a newspaper article entitled "The Secret Price War between Endesa and Iberdrola", Mota (2003) writes: "Why is Iberdrola opposing the CTCs, apparently against such as primary and evident interest as to receive the money that it had been recognized or given by the government?...because it would hurt Endesa more, but above all, because the end of the CTCs would free the market price-now it is capped at $6 \mathrm{PTAS} / \mathrm{kWh}$-in which the Basque generator (Iberdrola) has a larger share than it has on the CTCs."
} 

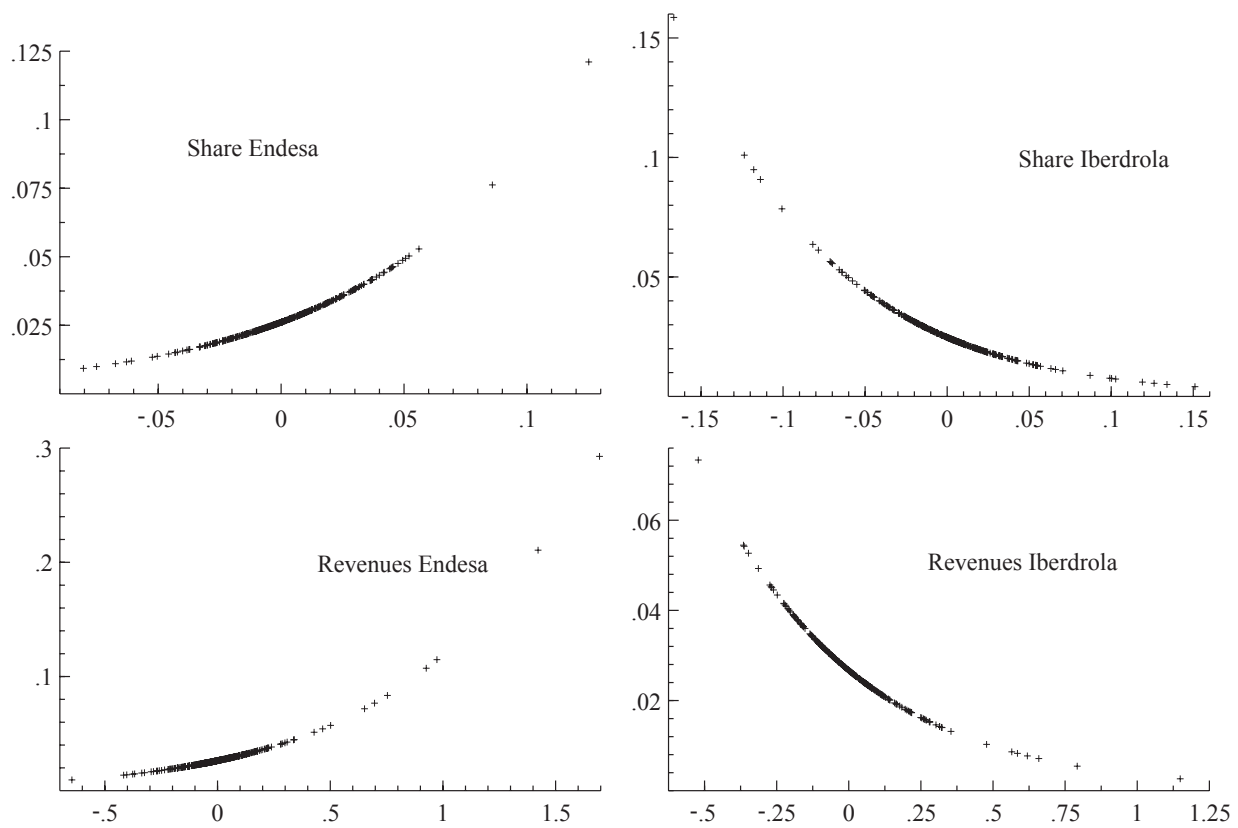

Fig. 4. Cross plots of trigger variables and the probability of starting a price war, $P\left(S_{t}=1 \mid S_{t-1}=0, w_{t}\right)$, for $\Delta$ Share $_{t-1}^{\mathrm{END}}, \Delta$ Share $_{t-1}^{\mathrm{IB}}, \Delta \operatorname{Rev}_{t-1}^{\mathrm{END}}$ and $\Delta \operatorname{Rev}_{t-1}^{\mathrm{IB}}$.

Fig. 5 plots the smoothed probabilities of being in a low state of prices for Model 1, which uses changes in Endesa's market share as the trigger variable. Smoothed probabilities are the inferred probabilities of being in a given state using all the information available. Though the smoothed probabilities slightly differ for the other models, they all deliver similar pictures. The classification of the states and the dating of the price wars is done using the smoothed probabilities. At every point in time, we calculate a smoothed probability of being in an given state, and then assign that

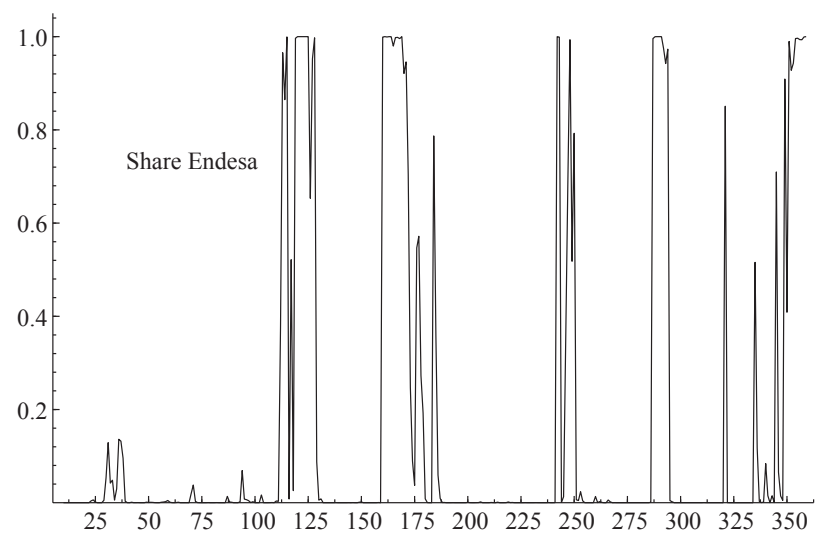

Fig. 5. Smooth probabilities of being in a price war (based on Model 1, trigger $\Delta \operatorname{Share}_{t-1}^{\mathrm{END}}$ ). 
Table 5

Dating of price wars, duration, depth, and generators' mark-ups in the period before a price war starts (based on Model 1, trigger $\Delta$ Share $_{t-1}^{\mathrm{END}}$ )

\begin{tabular}{lllcr}
\hline Dating & Duration (days) & Depth $(\%)$ & Markup $_{t-1}^{\text {END }}(\%)$ & Markup $_{t-1}^{\text {IB }}(\%)$ \\
\hline $04 / 05-13 / 05$ & 10 & 44.27 & -10.18 & -31.04 \\
$14 / 06-03 / 07$ & 20 & 41.21 & 8.80 & 15.95 \\
$08 / 09-12 / 09$ & 5 & 18.75 & -19.38 & -26.77 \\
$19 / 10-26 / 10$ & 8 & 34.16 & -4.63 & -2.02 \\
$20 / 12-30 / 12$ & 11 & 21.69 & 21.11 & 41.71 \\
\hline
\end{tabular}

observation to one of the regimes according to the highest filtered probability, i.e., we classify period $t$ as a high-price state if $P\left(S_{t}=1 \mid S_{t-1}=s_{t-1}, w_{t}, \mathrm{SMP}_{t}\right)<0.5$, as a low-price state if $P\left(S_{t}=1 \mid S_{t-1}=s_{t-1}, w_{t}, \mathrm{SMP}_{t}\right)>0.5$. This rule minimizes the total probability of misclassification in the sample. We will consider the definition of a price war whenever a state of low prices is followed by a state of the same nature.

This definition allows a corresponding dating of price wars in the Spanish electricity market. As can be seen in Table 5, the average duration of a price war ranges from slightly less than five days to almost three weeks. ${ }^{31}$ The drops in prices during a price war regime with respect to the last collusive period-which we refer to as the depth of the price war-, are of great magnitude. On average, prices drop 32\% and the highest drops in prices attain values as high as $45 \%$. Furthermore, in line with the models of individual profit maximizing behavior among contracted firms (Newbery, 1998; Wolak, 2000), during the price war phase Endesa's mark-up is negative and Iberdrola's is positive. However, during the collusive phase, Endesa's mark-up becomes positive (Table 6).

Last, Table 7 reports a summary of evaluation statistics for each of the estimated models based on the predicted residuals. The diagnostic statistics comprise a Chi-square test for second-order residual error autocorrelation, an $F$-test for conditional heteroscedasticity of order two, as well as a Chi-square test for normality. Their corresponding $p$-values are reported in the first, second and third rows, respectively. The different models estimated seem to be a good statistical specification given the diagnostic statistics.

Implicit in our formulation is the assumption that the pattern of prices is characterized by two different states. However, one could argue that the asymmetry in firms' deviation incentives could allow punishment strategies to be tailored to the suspect, leading to three rather than two regimes. Unfortunately, testing for the number of regimes in a Markovswitching model is a difficult task. First, the conventional testing approaches to deal with the number of regimes are not applicable due to the presence of unidentified nuisance parameters under the null of linearity (that is, the transition probabilities). And second, the scores associated with the parameters of interest under the alternative hypothesis may be identically zero under the null. Formal tests of the number of regimes within the Markovswitching framework employing the standardized likelihood ratio (LR) test designed to

\footnotetext{
31 The results reported in Table 5 rely on the regime classification obtained using the smooth probabilities of the model where $\Delta$ Share $_{t-1}^{\mathrm{END}}$ is the trigger variable. This regime classification hardly changes across the different models. Further results on the regime classification using other models can be obtained from the authors upon request.
} 
Table 6

Average markups during collusive and price war periods (based on Model 1, trigger $\Delta$ Share $_{t-1}^{\mathrm{END}}$ )

\begin{tabular}{lcc}
\hline & Markup $^{\mathrm{END}}(\%)$ & Markup $(\%)^{\mathrm{IB}}$ \\
\hline Collusive periods & 18.27 & 31.80 \\
Price war periods & -11.70 & 4.10 \\
\hline
\end{tabular}

deliver (asymptotically) valid inference have been proposed by Davies (1977), Hansen (1992, 1996) and Garcia (1993). The extension of Hansen's approach to our model seems to be impossible to implement computationally (see Ang and Bekaert, 1998) and is certainly beyond the scope of this paper. Furthermore, it delivers only a bound on the asymptotic distribution of the standardized LR test. The test is conservative, tending to be under-sized in practice, and of low power. Nevertheless, we estimated a three regimes' equation for all the models entertained. A LR test of two regimes against the alternative of three delivered the following values: 4, 2.01, 10.05, 7.75, 3.11 and 1.79, for Models 1 to 6 as presented in Table 3. Even if we used the upper bound suggested in Davies (1977), the null of a two states model cannot be rejected against the alternative of three states for all the models.

\subsection{Is the evidence consistent with Green and Porter (1984)?}

The regime-switching models of the type pioneered by Green and Porter (1984) (GP) provide a possible explanation for the evidence reported above (see also Abreu et al., 1986). In these models, firms move between cooperative and punishment periods (price wars) as a way to enforce collusive outcomes. Under imperfect monitoring (i.e., imperfect information about firms' past actions or market conditions), firms are unable to distinguish whether changes in the observable variables are due to changes in market conditions or to cheating by one of the cartel members. Thus, in order to discourage deviations, reversions to some short-run unprofitable behavior must be employed when one of the observable variables behaves as if a deviation had occurred.

The Spanish electricity market departs from the classic GP's formulation in two respects. First, the underlying games differ, and so do their implications for the patterns of switches that are consistent with the theory. As analyzed in Section 3, firms' optimal deviations in the Spanish electricity market need not necessarily involve price undercutting. Hence, a large price reduction, which GP use as trigger, may not always be a good

Table 7

Specification tests

\begin{tabular}{|c|c|c|c|c|c|c|}
\hline & $\begin{array}{l}\text { Model 1, } \\
\Delta \text { Share }_{t-1}^{\text {END }}\end{array}$ & $\begin{array}{l}\text { Model 2, } \\
\Delta \text { Share }_{t-1}^{\mathrm{IB}}\end{array}$ & $\begin{array}{l}\text { Model 3, } \\
\Delta \mathrm{HHI}_{t-1}\end{array}$ & $\begin{array}{l}\text { Model 4, } \\
\Delta \overline{\mathrm{SMP}}_{t-1}\end{array}$ & $\begin{array}{l}\text { Model 5, } \\
\Delta \operatorname{Rev}_{t-1}^{\text {END }}\end{array}$ & $\begin{array}{l}\text { Model 6, } \\
\Delta \operatorname{Rev}_{t-1}^{\mathrm{IB}}\end{array}$ \\
\hline Error autocorrelation & 0.75738 & 0.76678 & 0.73609 & 0.71530 & 0.74595 & 0.85982 \\
\hline $\mathrm{ARCH}$ & 0.16598 & 0.17418 & 0.18635 & 0.18900 & 0.19316 & 0.18446 \\
\hline Normality & 0.93584 & 0.89554 & 0.98523 & 0.98342 & 0.92794 & 0.89832 \\
\hline Likelihood test & 0.00098 & 0.00052 & 0.00121 & 0.00114 & 0.00055 & 0.00073 \\
\hline
\end{tabular}


signal of cheating; accordingly, it is not clear whether it should be expected to trigger price wars.

The other difference with respect to GP is related to the information available to the Spanish electricity producers. In particular, in contrast with GP who assume that only prices but not quantities are observed, the Spanish electricity producers observe both aggregate quantities and prices at gate-closure. Nevertheless, this does not imply that the Spanish electricity producers may perfectly detect their rivals' potential deviations. First, the generation coming from the must-run resources (mainly, cogeneration and renewables) is not known. And second, firms' available capacities are subject to random shocks, out of firms' control (e.g. capacities may suffer random outages, or be increased due to an excess of run of the river hydro power). This implies that a firm's departure from any agreed upon market share may have resulted either from cheating by a rival, or from any of those random and unobservable factors cited above. Therefore, even if the sources of imperfect information differ, the Spanish electricity producers are faced with the same kind of signal extraction problem as in a GP type of model. ${ }^{32}$

To assess whether the evidence is consistent with GP, we proceed by comparing our empirical findings with their main predictions. First, the fact that two distinct price levels characterize the time series of prices in the Spanish electricity market confirms GP's prediction that price wars should be observed in equilibrium. Second, the statistical significance of the trigger variables is consistent with GP's prediction that price wars must be linked to movements in the trigger variables. Third, since the effects of the triggers coincide with the theoretical findings, GP's prediction that price wars should be more likely to occur when the trigger variables move as if a deviation had taken place is confirmed. Unfortunately, the lack of data on individual bids does not allow us to test GP's prediction that deviations should not take place in equilibrium. Nevertheless, the information contained in Table 5 may shed some light on this issue. It shows that the behavior of firms' mark-ups in the period that triggers the price war is not homogenous across the different price wars, probably suggesting that deviations are not taking place (or at least, not always in the same direction).

Having said all this, there are other reasons that indicate caution regarding interpretation of the evidence as support for GP's model. The incentive structure embedded in GP's model requires a high degree of rationality, which cannot be reasonably expected in a market that has only recently started to operate. Furthermore, firms' optimal deviations in GP's model are symmetric, implying that movements in the trigger variables do not convey any information about the potential deviator. In our case, the asymmetry in firms' deviation incentives should in principle allow punishments to be tailored to the suspect. The fact that a three-state model is rejected in our data contradicts the use of an

\footnotetext{
32 There is an alternative branch of the literature on collusion in markets subject to variable demand, exemplified by the models of Rotemberg and Saloner (1986) and Haltiwanger and Harrington (1991). In these models, which assume perfect monitoring, price wars do not arise as equilibrium phenomena. Instead, the sustainability of collusion is maintained through smoother price adjustments, which depend on current or future demand conditions. However, we believe that perfect monitoring is an unrealistic assumption in the Spanish electricity market.
} 
optimal collusive device, and hence casts some doubts on the applicability of GP's model to our data set.

Indeed, there could be several alternative explanations, other than collusion, for the phenomena that we observe in the Spanish data. For instance, if firms were not pursuing collusive strategies, the existence of periods of low prices could be accounted for by mixed strategy pricing or by the lack of coordination on the multiple price equilibria (see von der Fehr and Harbord, 1993). However, if this were the case, there should be no reason to observe such a persistence in each price state as we observe in the data. Furthermore, there should not be a systematic relationship between the trigger variables and the occurrence of price wars, i.e., their coefficients should be non-significant.

\section{Conclusions}

We have analyzed the dynamic exercise of market power in the Spanish electricity market during 1998 using daily observations on demand, prices and other variables that allow us to obtain accurate marginal costs estimates at the firm level. The Spanish electricity market has interesting institutional features that make this analysis relevant both for public policy, as well as from a methodological perspective.

As in all decentralized electricity markets, trading in the Spanish electricity market takes place through a series of daily auctions. Both theory and experience suggest that the daily repetition of auctions may have a dramatic effect on market performance, as it allows firms to learn to coordinate their strategies and hence compete less aggressively with each other over time, through collusive agreements. However, unlike other markets, collusion in the Spanish electricity market need not result in high price-cost margins, precisely because the Spanish electricity producers are entitled to earn some regulatory payments, which are computed in a similar fashion as "Contracts for Differences". The theoretical predictions imply that an over-contracted firm may find it in its private interest to reduce prices, as this strategy may lead to an increase in its contract revenues that more than compensates for the reduction in prices. Thus, even in a static context, the value of firms' mark-ups does not provide a precise measure of firms' ability to exercise market power. To overcome this difficulty, our analysis has exploited the movements in prices, firms' market shares and revenues in order to infer firms' ability to exercise market power in a dynamic context.

The performance of the Spanish electricity market during 1998 is not consistent with the predictions of models of individual profit maximizing behavior. In particular, the overcontracted firm should have produced at prices below marginal costs, and the movements in prices should have been fully explained by changes in demand and cost conditions. These observations have led us to conjecture that the Spanish electricity producers may have been engaged in some kind of tacit agreement that distorted market outcomes from the predictions of the theories of individual profit maximizing behavior.

Our analysis has been designed to test the above conjecture. In order to identify the plausible triggers that firms could have used to support collusion, we have first identified firms' optimal deviations from a model of joint-profit maximizing behavior. This model predicts that price wars should be triggered when the market share and revenues of the under-contracted firm decrease, and those of the over-contracted firm increase. We have 
tested these predictions empirically by modelling the time series of prices as a Markovswitching process in the mean, with time-varying transition probabilities that depend on changes in firms' market shares, revenues, and market prices. The results confirm that the time series of prices is characterized by two distinct price levels. Furthermore, most of the triggers considered appear to be significant and report the same signs as those predicted by the theory. These results offer further support to the claim that the way in which the CTCs have been computed has had an important impact in firms' bidding incentives.

\section{Acknowledgments}

Special thanks are due to Giulio Federico, Soren Johansen and Massimo Motta. James Bushnell, Kristi Green, Iñigo Herguera, Ed Kahn, Matt Shum, Steve Puller and seminar participants at the University of California Energy Institute (2003 POWER Conference), Universidad Carlos III de Madrid (2002 EARIE Conference), and Universidad Complutense de Madrid (February 2003) provided helpful suggestions. Detailed comments by two anonymous referees and the Editor, Igal Hendel, also contributed to improve the paper. Antonio Jesús Sánchez provided excellent research assistance. All errors remain our own responsibility. Research reported in this paper was partly carried out while the first author was at the IDEI (Toulouse) and the UCEI (Berkeley) and the second author was at Oxford University; we are indebted to them for their hospitality and encouragement.

\section{References}

Abreu, D., Pierce, D., Stacchetti, E., 1986. Optimal Cartel equilibria with imperfect monitoring. Journal of Economic Theory 39, 251-269.

Ang, A., Bekaert, G., 1998. Regime Switches in Interest Rates. Working Paper, Stanford University.

Arocena, P., Kuhn, K.-U., Regibeau, P., 1999. Regulatory reform in the Spanish electricity industry: a miss opportunity for competition. Energy Policy, 387-399.

Borenstein, S., Bushnell, J., 1999. An empirical analysis of the potential for market power in California's electricity industry. Journal of Industrial Economics XLVII (3), 285-323.

Borenstein, S., Bushnell, J., Wolak, F., 2002. Measuring market inefficiencies in California's restructured wholesale electricity market. American Economic Review 92 (5), 1376-1405.

Bushnell, J., 2003. A mixed complementarity model of hydro-thermal electricity competition in the Western U.S. Operations Research 51 (1).

CNE, 2000. El Funcionamiento del Mercado Eléctrico en el Año 1998. Technical report, Comisión Nacional de la Energía, Madrid.

Crampes, C., Fabra, N., in press. The Spanish electricity industry: plus ça change..., Energy Journal.

Davies, R.B., 1977. Hypothesis testing when a nuisance parameter is present only under the alternative, 64, 247-254.

Ellison, G., 1994. Theories of Cartel stability and the joint executive committee. Rand Journal of Economics 25, $37-57$.

Engle, R.F., Hendry, D.F., Richard, J., 1983. Exogeneity. Econometrica 51, 277-304.

Fabra, N., 2003. Tacit collusion in repeated auctions: uniform versus discriminatory. Journal of Industrial Economics L1 (3), 271-293.

Fabra Utray, J., 2004. Un Mercado Para la Electricidad: Liberalización o Regulación? Marcial Pons, Madrid. 
Filardo, A., 1994. Business-cycle phases and their transitional dynamics. Journal of Business Economics and Statistics 12, 299-308.

Garcia, R., 1993. Asymptotic null distribution of the likelihood ratio test in Markov switching models. Technical report, Université de Montréal.

Green, R., Newbery, D., 1992. Competition in the British electricity spot market. Journal of Political Economy 100, 929-953.

Green, E.J., Porter, R.H., 1984. Noncooperative collusion under imperfect price information. Econometrica 52 (1), $87-100$.

Haltiwanger, J., Harrington, J., 1991. The impact of cyclical demand movements on collusive behavior. Rand Journal of Economics 22, 89-106.

Hamilton, J.D., 1989. A new approach to the economic analysis of nonstationary time series and the business cycle. Econometrica 57, 357-384.

Hansen, B.E., 1992. The likelihood ratio test under non-standard conditions: testing the Markov Switching Model of GNP. Journal of Applied Econometrics 7, S61-S82.

Hansen, B.E., 1996. Erratum: the likelihood ratio test under non-standard conditions: testing the Markov Switching Model of GNP, 11, 195-199.

Joskow, P., Kahn, E., 2002. A quantitative analysis of pricing behavior in California's wholesale electricity market during Summer 2000. The Energy Journal 22 (4), 1-35.

Marín, P., García-Díaz, A., 2003. Strategic bidding in electricity pools with short-lived bids: an application to the Spanish market. International Journal of Industrial Organization 21, 201-222.

Mota, J., 2003. La Guerra Secreta Entre Endesa e Iberdrola. El Pais Negocios 18 (November).

Newbery, D., 1998. Competition, contracts, and entry in the electricity spot market. Rand Journal of Economics 29 (4), 726-749.

Patrick, R., Wolak, F., 1997. The impact of market rules and market structure on the price determination process in the England and Wales electricity market. Working Paper, PWP-047, University of California, POWER.

Puller, S., 2000. Pricing and firm conduct in California's deregulated electricity market, PWP-080. UCEI, California.

Rotemberg, J., Saloner, G., 1986. A supergame theoretic model of price wars during booms. American Economic Review 70, 390-407.

von der Fehr, N., Harbord, D., 1993. Spot market competition in the UK electricity industry. The Economic Journal 103, 531-546.

Wolak, F., 2000. An empirical analysis of the impact of hedge contracts on bidding behavior in a competitive electricity market. International Economic Journal 14 (2), 1-39.

Wolak, F., 2003. Measuring unilateral market power in wholesale electricity markets: the California market, 1998-2000. American Economic Review, Papers and Proceedings May, 425-430.

Wolfram, C., 1998. Strategic bidding in a multi-unit auction: an empirical analysis of bids to supply electricity in England and Wales. Rand Journal of Economics 29 (4), $703-725$.

Wolfram, C., 1999. Measuring duopoly power in the British spot market. American Economic Review 89, 805-826. 